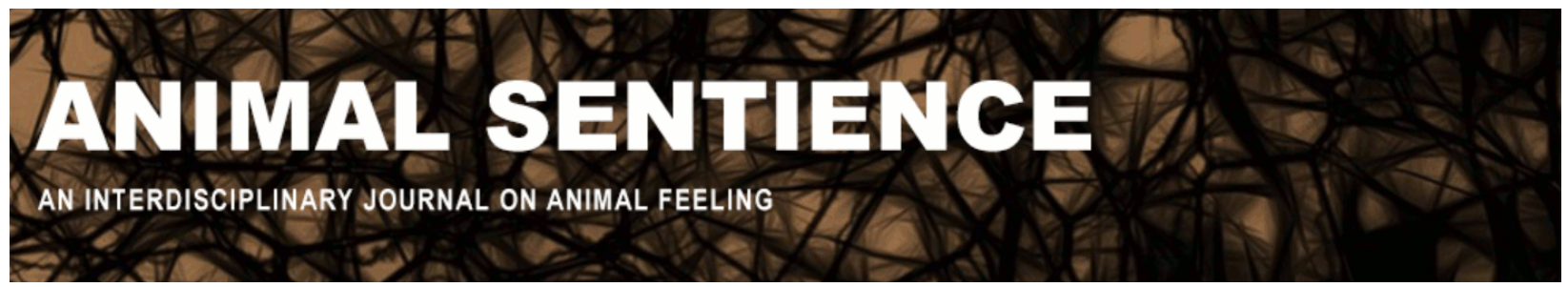

Willett, Cynthia (2019) Can a mirror capture the self?. Animal Sentience 25(36) DOI: $10.51291 / 2377-7478.1467$

Date of submission: 2019-05-29

Date of acceptance: 2019-06-13

(c) (i)




\title{
Can a mirror capture the self?
}

Commentary on Marino \& Merskin on Sheep Complexity

\author{
Cynthia Willett \\ Philosophy Department \\ Emory University
}

\begin{abstract}
Is the mirror a reliable indicator of self-awareness for any species, whether sheep or human? Taking a cue from feminist, phenomenological, and cross-cultural philosophy, a relational self rather than a reflective one might better capture what is at stake for the lives of social animals and for science.
\end{abstract}

\begin{abstract}
Cynthia Willett is Samuel Candler Dobbs Professor of Philosophy at Emory University. Her books include Interspecies Ethics (Columbia University Press, 2014) and (with historian Julie Willett) Uproarious: How Feminists and Other Subversive Comics Speak Truth (University of Minnesota, 2019; open access), including research on human and nonhuman primates, horses, and corvids as tricksters and jokers. Website
\end{abstract}

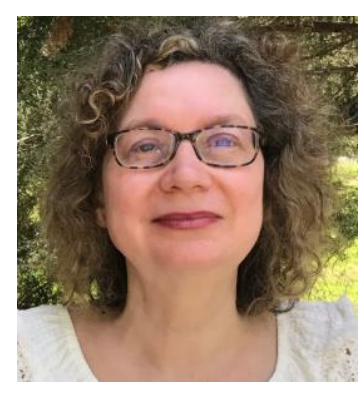

Marino \& Merskin (2019) (M\&M) report that mirror recognition is not among the sheep's many cognitive capacities, leaving open the question of whether they have a sense of self. In response, Abbate (2019) points out that canines, too, fail the mirror test and yet show self-awareness not through visual means, but through their sense of smell. They seem to recognize their "yellow snow." However, is mirror-recognition a reliable indicator of self-knowledge for any species? Even for humans?

The mirror-recognition test ignores variance in sensory modes of awareness across species. Some animals are clearly less attuned to themselves through visual images than through smell or other sensory modalities. But this test also obscures the variance in the kinds of selves across human and nonhuman animal cultures.

The mirror test assumes that reflection - and in particular the capacity to take the self as an object of thought (with or without the assistance of a mirror) - is the highest form of selfawareness. Yet there is nothing fixed about this configuration of the self. It has a history. One historian argues that this notion of the self has emerged as a dominant cultural idea with the migration from rural communities to the anonymity of cities and that it culminates with the rise of corporate culture (Wickberg, 2015). In these new environments, the ability to treat oneself as a distant object - to see oneself as would a stranger - lends a sense of perspective that is important for public life. This abstract relation to the self is critical for encounters where the human self is no longer defined as it once was - centrally, through social roles and expectations of close-knit communities. The notion of the self that is captured through the device of a mirror 
is not universal and unchanging. The mirror self - or at least its salience - appears at a particular time in history.

Phenomenology and comparative philosophy (Ram-Prasad, 2018) as well as feminist theory have challenged the dominance in our thought of the kind of self that the mirror test is designed to measure. Gilligan's (1993) important work on moral development and gender bias has extended philosophical ethics from a narrow focus on the self-reflective, principled individual - the self in the mirror - to an emotionally engaged and relational self who negotiates feelings toward a sense of social belonging.

Gender bias too seems to influence our understanding of sheep. M\&M report that sheep are represented in our culture as not very impressive animals - as submissive, less intelligent, and as predominantly female. What if, taking a cue from Gilligan, we shift the focus of our science from the standard measures of the self to the drama of sheep lives! Instead of merely listing capacities observed as though sheep were objects of study, we could also learn how they navigate their relationships and develop a sense of belonging through our own carefully negotiated encounters with them. Brooks Pribac's (2019) research on grief and attachment points to the importance of relationships for animal selves. So too do Peña-Guzmán's (2019) remarks on the scientist's need to attend to individual personalities and establish trust to motivate the participation of nonhumans in human experiments. Perhaps sheep fail the mirror test because that is not where their emotive center lies. M\&M's rich review begins to clear away the smoke and mirrors that obscure what we might be able to learn about sheep, about ourselves, and about possibilities for mutual trust and shared endeavors.

\section{References}

Abbate, C. (2019). Sheep complexity outside the laboratory. Animal Sentience 25(21). Brooks Pribac, T. (2019). Positive sentience is underrated. Animal Sentience 25(11). Gilligan, C. (2016). In a Different Voice. Cambridge, MA: Harvard University Press. Marino, L., \& Merskin, D. (2019). Intelligence, complexity, and individuality in sheep. Animal Sentience 25(1).

Peña-Guzmán, D. (2019). Casting a sheep's eye on science. Animal Sentience 25(6). Ram-Prasad, C. (2018). Human Being, Bodily Being: Phenomenological Case Studied from Classical India. Oxford: Oxford University Press.

Wickberg, D. (2015). The Senses of Humor: Self and Laughter in Modern America. Ithaca, NY: Cornell University Press. 